\title{
ON THE ROLE OF BENCHMARKING IN THE HIGHER EDUCATION QUALITY ASSESSMENT
}

\author{
Moise Ioan Achim ${ }^{1}$ \\ Lucia Căbulea ${ }^{2}$ \\ Maria Popa ${ }^{3}$ \\ Silvia - Ştefania Mihalache ${ }^{4}$
}

\begin{abstract}
Increasing competition, demands for accountability, and higher volumes of available information are changing the methods of how institutions of higher education operate in nowadays. For higher education to enact substantial and sustainable changes in efficiency and productivity a new way of thinking or paradigm that builds efficiency and a desire for continual learning must be integrated into institutional structures. Tools are also being developed that measure or benchmark the progress and success of these efforts. Among the improvement strategies and techniques, benchmarking has emerged as a useful, easily understood, and effective tool for staying competitive. This is why the present article aims to emphasize the importance of benchmarking in the higher education quality assessment.
\end{abstract}

Key words:benchmarking, higher education, quality, management

JEL codes: I21, O32, D23

\section{Introduction}

For most institutions of higher education the desire to learn from each other and to share aspects of good practice is almost as old as the university itself. With the emphasis on collegiality and the recognition of the international role of the university such desires have traditionally manifested themselves in numerous ways: professional associations, both academic and nonacademic, meeting to share common interests; numerous visits by delegations from one higher education system to examine practice in another; professional bodies working collaboratively with institutions in supporting academic provision and mediating standards; and where formal quality assessment or accreditation systems exist, their ultimate dependence upon the maintenance of the goodwill of universities often by providing their own staff to take part as assessors of other institutions. Thus improving performance by collaboration or comparison with other universities is nothing new in higher education.

What is new, however, is the increasing interest in the formalization of such comparisons, and this short monograph reports on one recent innovation in this area: the development of benchmarking in higher education.

\footnotetext{
1 “1 Decembrie 1918” University of Alba Iulia, 11-13 Nicolae Iorga Street, Alba Iulia, Romania, achimmoise@yahoo.com;

2 “1 Decembrie 1918” University of Alba Iulia, 11-13 Nicolae Iorga Street, Alba Iulia, Romania, cabuleal@uab.ro;

3 “1 Decembrie 1918” University of Alba Iulia, 11-13 Nicolae Iorga Street, Alba Iulia, Romania, mariapopa2010@yahoo.com;

4 “1 Decembrie 1918” University of Alba Iulia, 11-13 Nicolae Iorga Street, Alba Iulia, Romania, sylvia_mihalache@yahoo.com;
} 


\section{Quality}

Traditionally, quality in higher education was seen in terms of the 'exceptional'. By its very nature, elitist higher education recruited exceptional teachers, researchers and students and provided them with exceptional libraries, laboratories and opportunities to learn from one another. 'Excellence' was the clarion call of all universities. The emphasis was on high quality inputs. The result was 'excellent' outcomes - pioneering research, scholarly theses and exceptional graduates, who were attractive to employers simply by dint of being graduates (Harvey, 2007).

'Quality' has also become used as shorthand for the bureaucratic procedures applied to monitor various notions of quality. It is thus not the quality itself that is regarded as undesirable, but the paraphernalia of quality monitoring that is seen as so intrusive. Quality is not so much about what or why, but about assurance and assessment. It is about who decides what an appropriate educational experience is, for what purposes and at what cost.

'Quality' is about academic autonomy, about expanding and improving higher education systems.

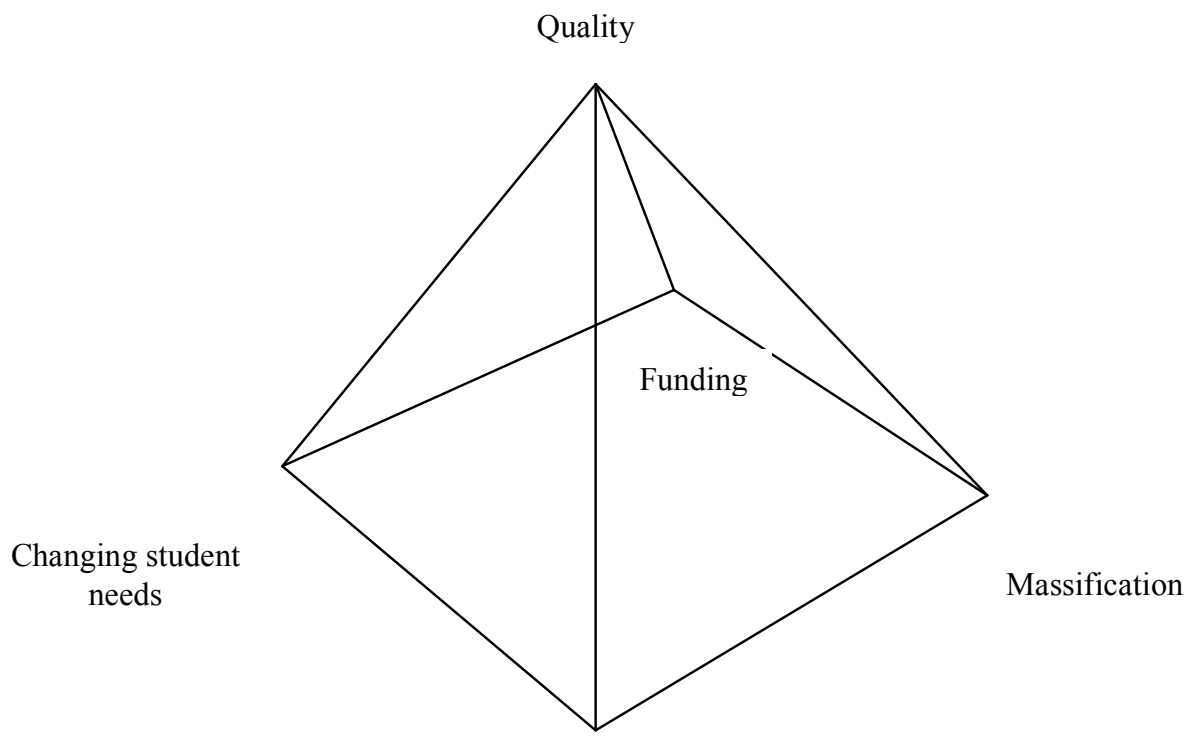

Academic authonomy

Fig. no. 1 - Quality in Higher Education

Source: Harvey, 2007

Cynicism about 'quality' in higher education is thus superficially linked to a view that it involves an agenda being controlled from outside academia. The changing perceptions of 'quality', from something intrinsically 'good' to something to be treated with suspicion, reflects the complex inter-relationship in higher education between massification, funding, academic autonomy, and changing student needs (see Fig. no. 1).

Massification and the changing needs of students in themselves reflect the pressure of international competition and the internationalization of labour markets. 'Quality' becomes the focus of attack or derision from those within academia reluctant to face up to changing student needs and preferring an introverted cloisterist approach (as opposed to a responsive collegialism). 'Quality', conversely, becomes the legitimating for ever more insidious managerialism. It 'conceals' the underfunding of mass/fled systems and it brings with it overbearing and bureaucratic accountability. We 
should be focusing on 'quality' at the pinnacle of the pyramid, but also on the elements on the base of it.

A dominant characteristic of European educational policy in the last decade is the systematic evaluation of higher education institutions undertaken as a consequence of indirect pressure from or by the direct initiative - of governing authorities. The evaluation methods which are used often combine self-evaluation with external evaluations and various forms of external reporting. In what is known as quality audits, the evaluation focus is on the higher education institution as a whole, where the objectives are often coupled to the desire to support universities and colleges in their attempts to redefine their mission, their activities and organization, and to stimulate and renew their way of dealing with the expectations of both society and students.

\section{Higher Education Quality Assessment (Quality Management)}

At the macro-level quality assessment is about power and control. At the micro-level it is about student experience and achievement. With the growth in the demand for higher education, the micro-level processes have become more visible, more important and more costly to society. External quality assessment is, therefore, used as a means to subject higher education institutions to wider public scrutiny.

External quality assessment systems are now fast becoming a global phenomenon. At the same time, individual higher education institutions are devoting more attention to internal assessment and evaluation. To some extent, these two trends are dearly connected; institutions are looking at their internal quality because of the expectations of external quality bodies. But they are doing so for a lot of other reasons as well - reasons to do with growth, with diversification, with financial cutbacks. These changes in the external environment pose questions of choice and decision-making for institutions and internal assessment and evaluation processes can inform these decisions.

In several recent papers, Martin Trow (1996) has questioned the compatibility between internal evaluation processes which are designed to address internal needs and problems and internal evaluation processes which feed into the requirements of external quality bodies. The first type he describes as being primarily about learning and the second type primarily about persuasion. Trow questions whether the two functions can be achieved within the same process.

Some authors claim that it all depends on context and that the three crucial elements of context are: (1) the general state of relationships between higher education and government (including the level of trust between the two); (2) the methods adopted by the external assessment agency (including the extent of standardization and whether rankings or league tables are involved); and (3) the character of the higher education institution itself (with factors such as reputation, pace of change and external threats all being important).

The relationships between student skills, knowledge and achievement, the require merits of the workplace, professional body requirements, promotion of the department and marketability of students have all been brought into sharper focus because of the institution's quality assessment systems.

Internal quality assessment and evaluation activities are resulting in quite major institutional changes and developments in higher education institutions in several countries. (It is equally true that major institutional changes and developments frequently drive quality assurance and evaluation. The relationship between institutional change and quality assessment and evaluation is a reciprocal one.)

The rewards - to both individuals and institutional units - associated with positive assessment results (whether internal or external) appear to be increasingly important, particularly when they result from assessment processes which command strong legitimacy among academic peers. Although rewards of money are important in some places, it is the reward of reputation which is most strongly sought. 
External quality assessment and evaluation may have relatively limited direct effects upon institutions. This supports Trow's view that externally driven institutional review and evaluation activities tend to be about persuasion and explanation and not about learning. There may, however, be important indirect impacts. In some countries, it is undoubtedly the case that the introduction of external quality assessment has been a powerful part of the external context which has stimulated internal attention to quality issues.

One of the factors associated with the impact of external quality assessment may be the extent of the standardization of the methods used in a particular country. Our case studies show how internal assessment and evaluation is frequently stimulated by quite particularistic institutional problems and needs. Where external assessment and evaluation methods are standardized, they are likely to fail to address institutions' own issues in the ways and to the timescales that the institutions would find most useful.

If external quality assessment seems to have only an indirect and fairly limited effect on quality improvement, it may still have an important accountability role to play. Although external quality assessment processes appear to have discovered remarkably little really had quality anywhere in the world, they may nevertheless be important to satisfy governments that the quality of higher education is satisfactory. Thus our final conclusion is that external quality assessment processes will remain necessary in those countries where governments do not trust their higher education institutions.

\section{Benchmarking}

Definitions of benchmarking vary widely, from the practical 'a self-improvement tool for organizations which allows them to compare themselves with others, to identify their comparative strengths and weaknesses and learn how to improve. Benchmarking is a way of finding and adopting best practices'; to the participative 'the open and collaborative evaluation of services and processes with the aim of emulating best available practice'; through to the global and ambitious "benchmarking is the process of continuously comparing and measuring an organization with business leaders anywhere in the world to gain information, which will help the organization take action to improve its performance" (American Productivity and Quality Center 1993).

The benchmarking concept is also defined in the following ways: 'the process of measuring and comparing the performances of a business with similar processes extent within the main organizations in order to obtain information which will help the organization to identify and implement improvements' or 'the continuous process of measuring products, services and business methods belonging to your own company, in comparison to the ones of the most powerful competitors and of those companies which are know as being industry leaders'.

Gerald Balm defines benchmarking in the following way: 'The continuous action of comparing a process, a product or a service with a similar activity, known as being the best in that field, with the purpose of establishing ambitious but real improvement objectives and actions so as to become and keep the number one position among the best within a reasonable period of time'.

Xerox, the firs company that ever used this method, called it 'a continuous search process for new ideas, methods and practices, for processes and for adjustment of these practices; or the adaptation of some good ideas and their real life application so as to become the first among the best'.

In Robert Camp's vision, 'Benchmarking is the continuous assessment process of our products, services and methods in comparison to those of our most serious competitors or of an enterprise recognized as being the leader in their field'.

In the face of such potential confusion, a number of sources have found it easier to describe what processes characterize typical benchmarking rather than trying to define it. Thus it is generally recognized that benchmarking is a means of making comparisons of performance, usually with a view to establishing 'good' - or more ambitiously 'best' - practice methods, and as such it is also 
used to diagnose problems in performance and to identify areas of strength. Like the publication of performance indicators, benchmarking does not necessarily provide solutions to problems - it is an aid to judgment rather than a substitute for it.

In addition to concentrating on what benchmarking is, another way of identifying what constitutes it is to identify what it is not. Thus, the Innovation Network, a US-based higher education management consultancy group, makes the point that ideally benchmarking is not just 'comparative analysis' of how an institution matches up to others in terms of measures like studentstaff ratios, or graduation rates, because this "doesn't drive change" and "does not specifically focus on the practices which create superior performance". It is not "process reengineering'(where internal processes are examined and improved, without looking at other organizations' practice). It is not just a survey, where data is presented in aggregated or average terms; benchmarking studies, by contrast, draw attention to successful scenarios of practices - for the process or function. Nor is it a "three-hour 'show and tell' session" with another institution, because "no improvement mechanism has been developed...nor have any measurements of success typically been put in place" (Innovation Network, 1994).

Other distinctions between what benchmarking is and is not were drawn by Spendolini (1992) in a important work for the American Management Association, when benchmarking was identified as: a continuous process and not a one-off event; a process that provides valuable information rather than simple answers; a process of learning from others rather than mere copying of ideas or practice; a time-consuming and labor intensive process rather than being quick and easy; and viable tool for improving virtually any business activity rather than a buzzword or fad.

The process oriented benchmarking within higher education seeks to answer some of the following questions: how well is the university or college doing compared to others? how good, and in what areas, does the university we want to be? across the university as a whole which part of it is doing best, and how do they do it? how can universities introduce into their own practice what is done well in others? how does an institution improve its performance while retaining its unique features? and - more competitively - in the longer term how an institution might become better than the best in the context of its own mission? For many in universities such questions will be provocative, 'and a challenge to the traditionally inward looking decision making systems of higher education.

So far as types of benchmarking are concerned, Alstete identifies four categories based upon the voluntary and proactive participation of institutions:

1. Internal benchmarking in which comparisons are made of the performance of different departments, campuses or sites within a university in order to identify best practice in the institution, without necessarily having an external standard against which to compare the results;

2. External competitive benchmarking where a comparison of performance in key areas is based upon information from institutions which are seen as competitors;

3. External collaborative benchmarking usually involves comparisons with a larger group of institutions who are not immediate competitors;

4. External trans-industry (best-in-class) benchmarking seeks to look across multiple industries in search of new and innovative practices, no matter what their source.

Separate from these types of benchmarking are the methodologies that institutions can adopt, and five main approaches are evident:

1. Ideal type standards (or 'gold' standards) whereby an model is created based on idealized best practice, and then used as the basis to assess institutions on the extent to which they fit that model;

2. Activity based benchmarking is a methodology in which a selected number of activities, which are either typical or representative of the range of institutional provision, are analyzed and compared with similar activities in other selected institutions. 
3. Vertical benchmarking seeks to quantify the costs, workloads, productivity and performance of a defined functional area, for example the work of a student admissions department.

4. Horizontal benchmarking on the other hand seeks to analyzed the cost, workloads, productivity, and performance of a single process that cuts across one or more functional areas, for example all aspects of student admissions irrespective of their location within an institution.

5. Use by institutions of comparative performance indicators is, as noted above, a highly questionable form of benchmarking, but a number of initiatives are reported below that are extremely important in influencing judgments being made about comparative performance within universities.

Benchmarking was developed in the US during the early 1980s at the Xerox Corporation "in response to increased competition and a rapidly declining market share". Since then it has proliferated in the business sector and an industry of services has arisen to support it. There are, for example, benchmarking clubs, networks and exchanges - groups of organizations that have formed collectivities to facilitate the sharing of information and the arrangement of visits for benchmarking purposes; there are numerous data sources and other resources available, sometimes at a price, for organizations that wish to benchmark independently of the established cooperatives; and there are software packages and consulting firms specifically focused on the conduct of benchmarking. A relevant example: CHEBA (Consortium for Higher Education Benchmarking Analysis) ${ }^{5}$ provides a forum for the exchange of performance measurements and benchmarking data for all levels of higher education around the world. The association is currently a free organization with fees assessed only when members want to join specific benchmarking efforts. Membership is limited to individuals employed as regular employees of public or private institutions of higher education.

In conclusion, benchmarking strengthens an institution's ability to successfully self-assess their institution; better understand the processes which support strategy formulation and implementation in increasingly competitive environments; measure and compare to the competition, i.e. how well are other higher education institutions in the sector performing, which higher education institutions are doing better and why; discover new ideas, looking out strategically; learn from others how to improve; obtain data to support decision-making with new strategic developments; set targets for improvement of processes and approaches in order to increase performance; strengthen institutional identity, strategy formulation and implementation; enhance reputation and better position the Institution; respond to national performance indicators and benchmarks; set new standards for the sector in the context of higher education reforms.

Benchmarking refers to a mechanism to learn from one's own experiences and from the experiences of others; learn for a purpose; and be aware of the fact that the organizational learning is a continuous process of systematic proactive continuous improvement, involving a cycle of enquiry, action, feedback and organizational memory.

Due to its reliance on hard data and research methodology, benchmarking is especially suited for institutions of higher education in which these types of studies are very familiar to faculty and administrators. Practitioners at colleges and universities have found that benchmarking helps overcome resistance to change, provides a structure for external evaluation, and creates new networks of communication between schools where valuable information and experiences can be shared. Benchmarking is a positive process, and provides objective measurements for base lining (setting the initial values), goal-setting and improvement tracking, which can lead to dramatic innovations (Shafer et Coate, 1992). In addition, quality strategies and reengineering efforts are both enhanced by benchmarking because it can identify areas that could benefit most from TQM (Total Quality Management), and make it possible to improve operations with often dramatic innovations. 
Despite the majority of positive recommendations for using benchmarking and successful examples of its current use, there are critics of its applicability to higher education. The stated objections include the belief that benchmarking is merely a strategy for marginally improving existing processes, that it is applicable only to administrative processes (or only to teaching practices), is a euphemism for copying, is lacking innovation, or that it can expose institutional weaknesses. These concerns are largely unfounded because benchmarking can radically change processes (if warranted), apply to both administration and teaching, adapt not 'adopt' best practices, and if the Benchmarking Code of Conduct is followed, confidentiality concerns can be reduced. The Code of Conduct calls for benchmarking practitioners to abide by stated principles of legality, exchange, and confidentiality. Benchmarking can make it possible for the industry to improve processes in a 'leapfrog' fashion by identifying and bringing home best practices, and therefore offering a way of responding to demands for cost containment and enhanced service quality in a cost-effective and quality-oriented manner (Shafer et Coate, 1992).

\section{Conclusion}

Although the specialty literature does not have too many works about benchmarking, the ones that exist were enough for us to understand the theoretic framework of the concept. The importance and the role of benchmarking were not discovered in the literature work but in practice.

In Romania, the Romanian Agency for Quality Assurance in Higher education, the agency whose mission is the evaluation and assurance of quality in higher education, has established, in compliance with the European norms an regulations, the standards and indicators for the quality assurance. This is why, in the visit records, among quality standards and indicators, one can find the following: the institution must have 'a central commission and study programme commissions which function in an integrated manner, promotes a quality culture within the institution, develops quality and quantity benchmarking activities by comparison with other universities inside the country and abroad for quality evaluation and monitoring'. These benchmarking activities also apply for the comparison of the study programme and diplomas that must be as the ones in EU, for the relation between teaching staff and students, and so one.

Also benchmarking activities are required by the quality assurance agency, it seems like few people now what benchmarking really means. It is very important not to mistake benchmarking activities with copying. Benchmarking means comparing, adopting good practices, continuous and organizational learning, a process that provides continuous development, innovation in order to become the best-in-class.

\section{References:}

1. Achim, M.I., Dragolea, L., 2009, Cercetare privind managementul calităţii serviciilor de învăţământ la Universitatea „1 Decembrie 19182 din Alba Iulia, Vol. Modele europene de adaptabilitate a întreprinderilor şi a lucrătorilor asimilabile pe piaţa muncii din România, Ed. Aeternitas Publishing House, ISBN 978-973-1890-41-8.

2. Brennan, J., Shah, T., Quality Assessment, Decision-Making and Institutional Change, in: Tertiary Education and Management, Vol.3, No. 2, 1997, 157-164.

3. Ellis, R. A., Moore, R. R., Learning through benchmarking: Developing a relational, prospective approach to benchmarking ICT in learning and teaching, in: Higher Education (2006) 51: 351-371.

4. Harvey, L., 2007, Quality Is Not Free! Quality Monitoring Alone Will Not Improve Quality, in: Tertiary Education and Management, Vol.3, No.2, 1997, 133-143.

5. Resnick, L. B., Nolan, K. J., Resnick, D. P., Benchmarking Education Standards, in: Educational Evaluation and Policy Analysis Winter 1995, Vol. 17, No. 4, pp. 438-461. 
6. Shafer, B.S., Coate, L.E. (1992). Benchmarking in Higher Education: A Tool for Improving Quality and Reducing Cost. Business Officer, 26(5), 28-35.

7. Seashore, K., Versloot, L. B., Standards and Cultural Diversity: Cautionary Tales of Comparative Research -A Comment on "Benchmarking Education Standards" by Lauren B. Resnick, Katherine J. Nolan, and Daniel P. Resnick, in: Educational Evaluation and Policy Analysis, 1996,Vol.18, No. 3, pp. 253-261.

8. Stensaker, B., Quality as discourse: an analysis of external audit reports in Sweden 1995-1998, available online at: http://www.emeraldinsight.com/.

9. Turner, D., Benchmarking in universities: league tables revisited, in: Oxford Review of Education Vol. 31, No. 3, September 2005, pp. 353-371.

10. ***Benchmarking in Higher Education, 1998, A study conducted by the Commonwealth Higher Education Management Service, Paris, available online at: http://unesdoc.unesco.org/images/0011/001128/112812eo.pdf.

11. ***European Network for Quality Assurance in Higher Education, 2003, Benchmarking in the Improvement of Higher Education, Helsinki, available online at: http://www.enqa.eu/files/benchmarking.pdf. 